\title{
EDTA-assisted phytoremediation of cadmium contaminated soil by Solanum nigrum L.
}

\author{
Yuqi $\mathrm{Li}^{1, \mathrm{a}}$, Xin $\mathrm{Pei}^{2}$, Jianyong $\mathrm{Li}^{2}$, Yonglin $\mathrm{Sun}^{1}$, Ying Liang ${ }^{1}$, Yansong $\mathrm{Ao}^{2, \mathrm{~b}}$ \\ ${ }^{1}$ School of Chemical Engineering and Food Sciences, Hubei University of Arts and Science, \\ Xiangyang, Hubei province 441053, China \\ ${ }^{2}$ School of agriculture and biology, Shanghai Jiao Tong University, Shanghai 200240, China \\ aemail: yuqi.li@hotmail.com, bemail:aoys@sjtu.edu.cn
}

Keywords: EDTA; Solanum nigrum L.; Phytoremediation; Cadmium; Soil contamination

\begin{abstract}
A pot experiment was performed to study the effect of EDTA (0, 1.5, $5.0 \mathrm{mmol} / \mathrm{kg})$ on the cadmium (Cd) accumulation ability of Solanum nigrum L. grown in different Cd-contaminated soils $(0,5,10,25,50,100$ and $200 \mathrm{mg} / \mathrm{kg})$. Meanwhile, soil Cd mobility was evaluated. Results showed that there were significant interactions between Cd and EDTA. Low EDTA dosage (1.5 $\mathrm{mmol} / \mathrm{kg}$ ) significantly alleviated Cd stress to S. nigrum L., although EDTA inhibited the growth of $S$. nigrum L. grown in non-contaminated soil. High EDTA dosage $(5 \mathrm{mmol} / \mathrm{kg})$ could deteriorate Cd stress to $S$. nigrum L. EDTA could significantly increase the mobility of soil Cd and the Cd content in plant. This research indicated that low EDTA dosage $(1.5 \mathrm{mmol} / \mathrm{kg})$ was efficient in assisting remediation of Cd contaminated soil by S. nigrum L. and could lessen second pollution.
\end{abstract}

\section{Introduction}

Cadmium (Cd) is considered to be one of the greatly hazardous heavy metals and included in the Environmental Protection Agency's list of priority pollutants[1]. It has been reported that the worldwide release of $\mathrm{Cd}$ reached 22000 t over the past five decades[2]. Once released, Cd tends to persist in the environment, especially in soil[3]. The cleanup of Cd contaminated soil is one of the most difficult tasks for environmental engineering[4]. Some methods, such as immobilization or extraction by physicochemical techniques, have an adverse effect on soil structure and require significant engineering costs[5]. Phytoremediation has been put forward since the late 1980s, to remove heavy metals from contaminated soil by harvesting the plants without damaging the soil. It has attracted much attention because it is environmentally friendly and cost-effective[6, 7].

Cd has limited solubility in soil and is generally not available for plant uptake due to soil adsorption and fixation [8,9]. Thus, efficient phytoextraction is often limited by the low bioavailability in soil and poor translocation from soil to plant shoot. Chelator assisted phytoextraction has been proposed to improve the efficiency of soil decontamination[10]. EDTA has been proved to be a strong and relatively bio-stable chelating agent that has potential for soil remediation applications [4, 11-13].

Solanum nigrum L., an annual or perennial weed, widely growing from the Variable Zone to the Torrid Zone in Asia, Europe and America, has been found to be a hyperaccumulator of Cd, which can grow naturally when contain more than $100 \mathrm{mg} / \mathrm{kg}$ dry weight Cd [14-17]. Meanwhile, it has a faster growth rate and larger shoot biomass compared to other discovered hyperaccumulators of Cd, such as Thlaspi caerulescens, Arabidopsis halleri and Viola baoshanensis [18-21]. Therefore, there is great potential for using S. nigrum L. in the remediation of Cd-contaminated soil and it may also provide a new resource for exploring the biochemical mechanisms of Cd hyperaccumulation and detoxification.

At present, there is no report about the interaction of EDTA with Cd to growth and Cd uptake of $S$. nigrum L. Therefore, the aims of this study are to evaluate the effect of EDTA on uptake of Cd by S. nigrum L. grown in different Cd contaminated soil. 


\section{Material and methods}

Soil treatment. Soil used in this experiment was obtained from the experimental farm, Shanghai Jiao Tong University. The soil was air-dried at room temperature and passed through a 2-mm sieve. Soil texture, $\mathrm{pH}$, electrical conductivity (EC) and organic carbon (C) were measured according to Bao [22]. $\mathrm{H}_{2} \mathrm{O}$-extractable $\mathrm{Cd}$ content in soil was measured using ICP-AES (Iris Advantage 1000). Table 1 shows the selected soil properties. Soils were treated using seven levels of Cd, which were $0,5,10,25,50,100,200 \mathrm{mg} / \mathrm{kg}$, respectively. Cd was added to soil as the form of $\mathrm{CdCl}_{2} \cdot 2.5 \mathrm{H}_{2} \mathrm{O}$ water solution. $2.4 \mathrm{~kg}$ of treated soil (equivalent dry weigh) was filled into the pot (15 cm in diameter and $18 \mathrm{~cm}$ in height) and each treatment included 30 pots. Treated soils were maintained $70 \%$ field water-holding capacity and equilibrated over three weeks for pot experiment.

Table 1 . The physicochemical properties of soil

\begin{tabular}{|c|c|c|c|c|c|c|}
\hline \multicolumn{3}{|c|}{ Soil texture (\%) } & \multirow{2}{*}{$\mathrm{pH}$} & \multirow{2}{*}{$\mathrm{EC}(\mu \mathrm{S} / \mathrm{cm})$} & \multirow{2}{*}{ Organic C (\%) } & \multirow{2}{*}{$\mathrm{Cd}\left(\mathrm{H}_{2} \mathrm{O}\right)(\mathrm{mg} / \mathrm{kg})$} \\
\hline Sand & Silt & Clay & & & & \\
\hline 22.2 & 59.7 & 18.1 & 7.2 & 250 & 1.99 & 0.014 \\
\hline
\end{tabular}

Pot experiment. The pot experiment was conducted in an environmentally controllable greenhouse (RICHEL, France) under condition of natural light. Day/night temperature of $18 / 30^{\circ} \mathrm{C}$ and humidity of $65 / 80 \%$ were applied. After germination, the seedlings of S. nigrum L. were pre-cultured for $30 \mathrm{~d}$ in the containers $(380 \times 277 \times 145 \mathrm{~mm})$ containing 1/2 Hoagland nutrient solution. And then, uniform seedlings of $S$. nigrum L. were selected and transplanted into each pot (1 plant per pot). After seedlings grew for $7 d$, each of $C d$ treatments was divided into 3 subgroups (10 pots per subgroup), which were treated using $200 \mathrm{~mL}$ of water solutions containing 0,3 and 12 mmol EDTA (disodium salt), respectively. Thus, EDTA concentrations in soil were 0 (E0), 1.25 (E1) and $5 \mathrm{mmol} / \mathrm{kg}$ (E2) at each of Cd treatments, respectively. After $10 \mathrm{~d}$ of EDTA treatment, four pots (replicates) were randomly selected in each treatment for plant and soil sampling.

Sample analysis. Soil samples collected were air-dried, ground and passed through a 2-mm sieve. Water-extractable $\mathrm{Cd}$ in soil was extracted with $1: 1$ soil:water ratio (w/v) and measured using ICP-AES (Iris Advantage 1000). EDTA-extractable Cd in soil was extracted with 1:5 ratio of soil to $0.05 \mathrm{~mol} / \mathrm{L}$ EDTA water solution (pH7.0, w/v) and measured using ICP-AES (Iris Advantage 1000).

Plants were gently removed from the soil and carefully washed with tap water. The roots and shoots were separated with scissors and washed with de-ionized water, and subsequently dried in an oven at $80^{\circ} \mathrm{C}$ to constant weight. The dry weights of the plants were measured. The plant materials were ground to pass through a 100 mesh sieve and digested with a mixture of $\mathrm{HNO}_{3}$ and $\mathrm{HClO}_{4}$ $(87 / 13, \mathrm{v} / \mathrm{v})$. Cd concentrations in the solutions were determined with ICP-AES (Iris Advantage 1000).

Data statistics. The results presented are the mean \pm standard errors of four replicates. Statistical analyses were performed using SPSS 11.5 statistical package for Windows. The level of significance used was $P=0.05$ in all statistical tests.

\section{Results and discussion}

Soil Cd availability. After EDTA application, there were significant increases in the contents of $\mathrm{H}_{2} \mathrm{O}$-extractable and EDTA-extractable $\mathrm{Cd}$ in Cd-contaminated soil (Figs. 1A and 1B). Regression analysis indicated that $\mathrm{H}_{2} \mathrm{O}$-extractable and EDTA-extractable $\mathrm{Cd}$ concentration in Cd-contaminated soil had significantly positive relations with the concentration of Cd applied at the each of EDTA dosages $\left(R^{2}>0.95, P<0.01\right) . \mathrm{H}_{2} \mathrm{O}$-extractable Cd contents at E1 and E2 treatments were 54 181 and 101 219 times than E0, respectively, which indicated that EDTA changed the soil $\mathrm{Cd}$ speciation. In each of Cd treatments, the order of the $\mathrm{H}_{2} \mathrm{O}$-extractable $\mathrm{Cd}$ content in soil was: E2 > E1 > E0. EDTA additions had no significant effects on EDTA-extractable Cd content in soil under $0-50 \mathrm{mg} / \mathrm{kg}$ Cd treatments, while significant differences were observed under $100-200 \mathrm{mg} / \mathrm{kg}$ $\mathrm{Cd}$ treatments compared to no EDTA addition $(P<0.05)$. At the treatments of 100 and $200 \mathrm{mg} / \mathrm{kg}$ $\mathrm{Cd}$, the order of the EDTA-extractable Cd content in soil was: E2 > E1 > E0. 
Although EDTA could facilitate metal transport from contaminated soil to plant due to enhanced mobility of metals in soil, the related risk of leaching to ground water could occur. EDTA tended to form metal complexes with high stability constants [23]. Metal-EDTA complexes were leached into the soil pore water and were found to be relatively bio-stable even under conditions of very favorable toward biodegradation [12]. Therefore, in practice, low EDTA dosage could lessen second pollution and was efficient in assisting phytoremediation of Cd from contaminated soil.
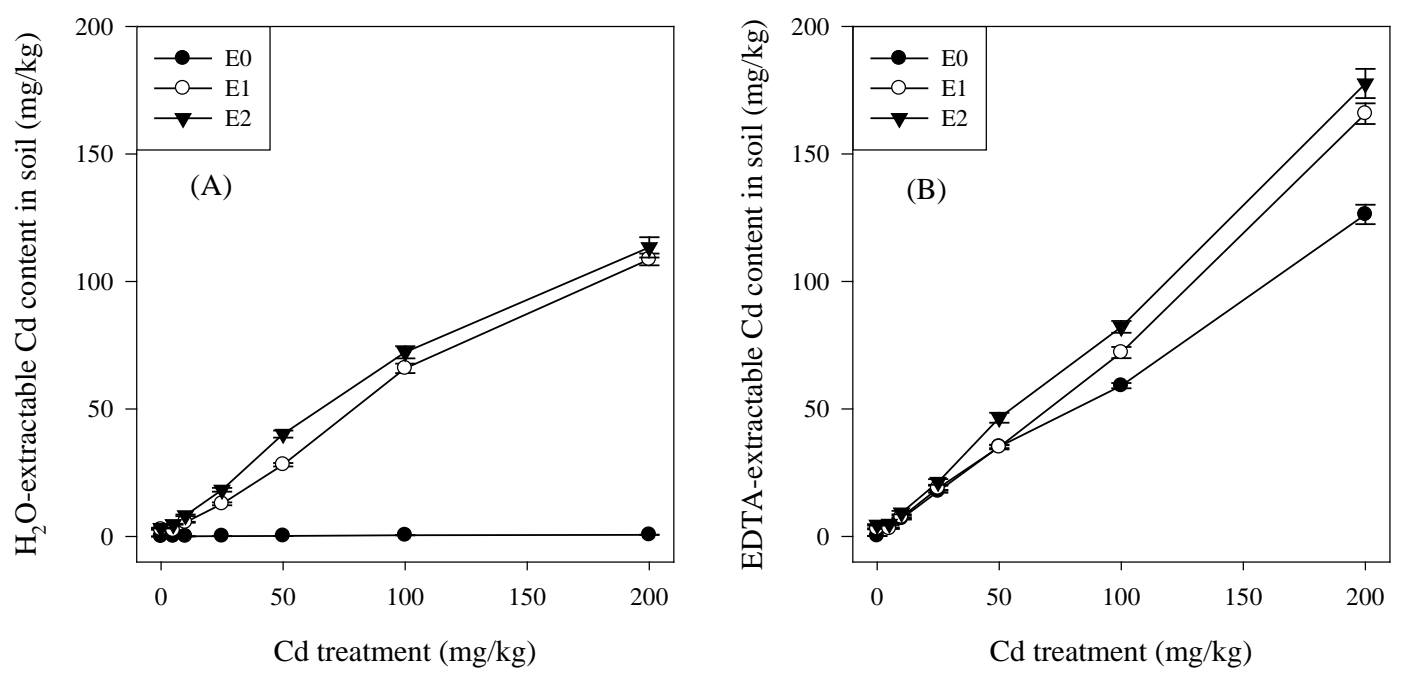

Fig. 1 Effect of EDTA (E0, 0; E1, 1.5; E2, 5 mmol/kg) on $\mathrm{H}_{2} \mathrm{O}$ - and EDTA-extractable Cd concentration in different $\mathrm{Cd}$-contaminated soils. The bars represented the standard errors.

Plant growth. Fig. 2A shows that the shoot dry matter yield of $S$. nigrum L. decreased with increasing the level of $\mathrm{Cd}$ applied to the soil and had significant differences among Cd treatments at each of EDTA dosages. Similarly, Sanità di Toppi and Gabbrielli [24] reported that Cd could inhibit plant growth and affect nutrient uptake and homeostasis. Application of low EDTA dosage (E1) significantly increased the shoot biomass of $S$. nigrum L., whereas high EDTA dosage (E2) significantly decreased the shoot biomass, compared to no EDTA application (E0) at each of Cd treatments expect $0 \mathrm{mg} / \mathrm{kg}$. Moreover, low EDTA dosage (E1) had more stimulating effects on the shoot biomass under the conditions of high soil Cd concentration than low soil Cd concentration. Low EDTA dosage (E1) increased the shoot biomass of S. nigrum L. by 6\%, 7\%, 9\%, 30\%, 84\% and $114 \%$ at the 5, 10, 25, 50, 100 and $200 \mathrm{mg} / \mathrm{kg}$ Cd treatment compared to no EDTA addition, respectively. At $0 \mathrm{mg} / \mathrm{kg}$ Cd treatment, EDTA significantly decreased the shoot biomass of $S$. nigrum L. These indicated that appropriate EDTA application could alleviate Cd stress to the growth of $S$. nigrum L. in Cd contaminated soil, although EDTA application inhibited the growth of $S$. nigrum L. in non-contaminated soil. In addition, changes of root biomass had similar trends to shoot (Fig. 1B).

Some studies indicated that EDTA could inhibit plant growth and cause great physiological damage [25, 26]. However, Wang, Lu [4] reported that EDTA had no significant effect on the growth of Bidens maximowicziana. The differences of these results were probably related with the amount of EDTA application, soil properties and plant species. 

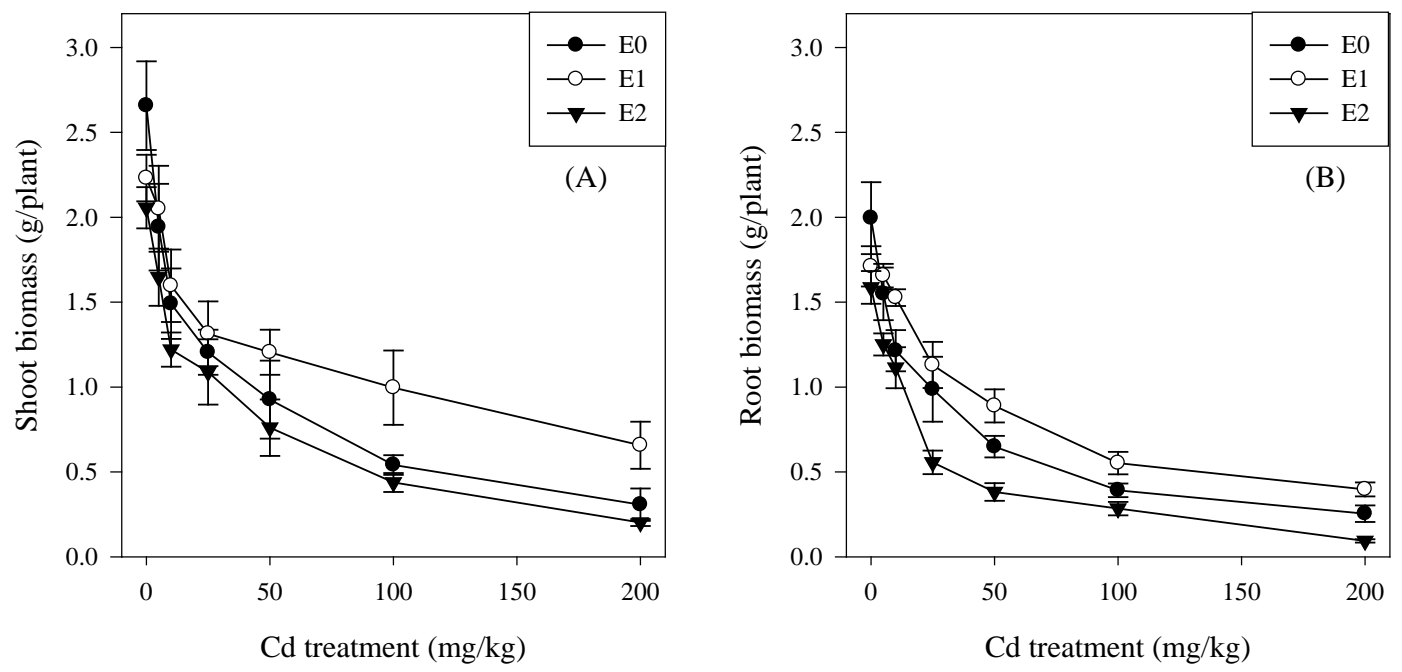

Fig. 2 Effect of EDTA (E0, 0; E1, 1.5; E2, 5 mmol $/ \mathrm{kg}$ ) on shoot (A) and root (B) biomass of $S$. nigrum $\mathrm{L}$. grown in different $\mathrm{Cd}$-contaminated soils. The bars represented the standard errors.
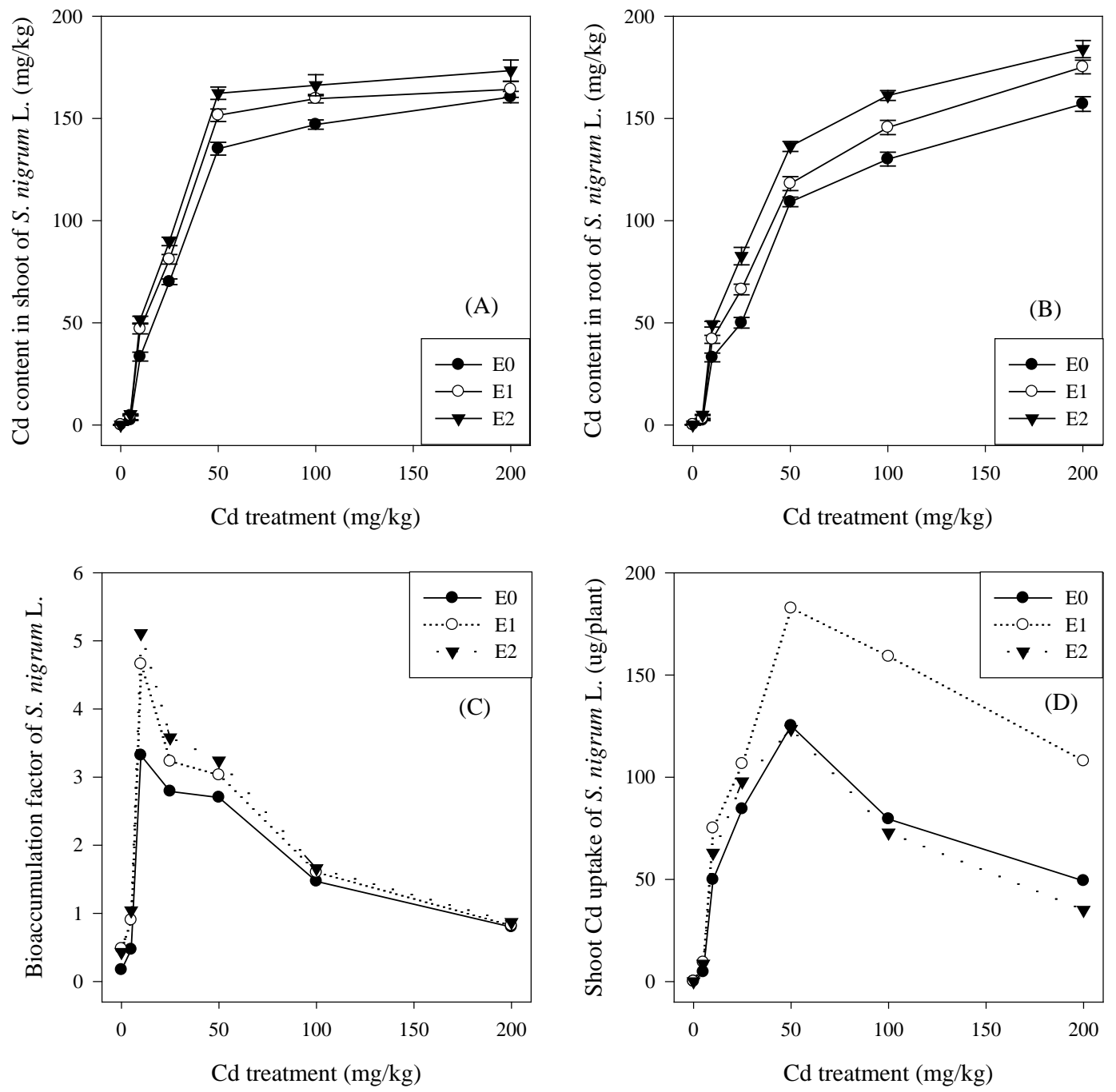

Fig. 3 Effect of EDTA (E0, 0; E1, 1.5; E2, $5 \mathrm{mmol} / \mathrm{kg}$ ) on the Cd contents in the shoots (A) and roots (B), bioaccumulation factor (C) and shoot Cd uptake (D) of S. nigrum L. grown in different

Cd-contaminated soils. Bioaccumulation factor was the ratio of the shoot Cd content to the concentration of Cd applied. Shoot Cd uptake was the product of shoot biomass and Cd content in the shoot. The bars represented the standard errors. 
Plant Cd uptake. Fig. 3A shows that the Cd content in shoot of S. nigrum L. significantly increased with increasing soil Cd concentration from 0 to $50 \mathrm{mg} / \mathrm{kg}$, but the Cd content in shoot did not significantly change from 50 to $200 \mathrm{mg} / \mathrm{kg}$ at each of EDTA treatments. Increased EDTA application significantly increased the Cd content in shoot at each of Cd treatments. The changes of Cd content in root had similar trends to shoot (Fig. 3B).

In this study, bioaccumulation factor is the ratio of shoot $\mathrm{Cd}$ content to the concentration of $\mathrm{Cd}$ applied. Fig. 3C shows that bioaccumulation factor had an increasing trend from 0 to $10 \mathrm{mg} / \mathrm{kg} \mathrm{Cd}$ treatment, while had a decreasing trend from 10 to $200 \mathrm{mg} / \mathrm{kg} \mathrm{Cd}$ treatment. At each of Cd treatments except $0 \mathrm{mg} / \mathrm{kg}$, the order of the bioaccumulation factor was: E2 > E1 > E0.

Phytoextraction efficiency was related to both plant metal concentration and dry matter yield [27]. Fig. 3D shows that shoot Cd uptake by S. nigrum L. increased from 0 to $50 \mathrm{mg} / \mathrm{kg} \mathrm{Cd}$ treatment and then decreased from 50 to $200 \mathrm{mg} / \mathrm{kg}$ Cd treatment at each of EDTA dosages. Low EDTA dosage (E1) significantly increased shoot Cd uptake compared to no EDTA addition. However, high EDTA dosage (E2) significantly increased shoot Cd uptake at low Cd treatment (0-25 mg/kg), had no significant effect on shoot Cd uptake at medium treatment $(50 \mathrm{mg} / \mathrm{kg})$ and significantly decreased shoot Cd uptake at high Cd treatment (100-200 mg/kg).

\section{Conclusion}

S. nigrum L. had a strong accumulation ability to $\mathrm{Cd}$. The mobility of soil $\mathrm{Cd}$ and the $\mathrm{Cd}$ concentrations in plants were both increased significantly by EDTA application. Low EDTA dosage $(1.5 \mathrm{mmol} / \mathrm{kg})$ could significantly alleviate Cd stress to S. nigrum L. and increase phytoextraction efficiency of Cd. High EDTA dosage $(5 \mathrm{mmol} / \mathrm{kg})$ significantly increased the Cd content in shoot, but deteriorated Cd stress to S. nigrum L. In practice, EDTA dosage and the applied area should be controlled for efficient phytoremediation and preventing probable second pollution.

\section{References}

[1] Roy E. Cameron. Guide to site and soil description for hazardous waste site characterization [R]. U.S. Environmental Protection Agency, Environmental Monitoring Systems Laboratory, 1992.

[2] O.V. Singh, S. Labana, G. Pandey, R. Budhiraja, R.K. Jain. Phytoremediation: an overview of metallic ion decontamination from soil [J]. Applied Microbiology and Biotechnology, 200361 (5-6) 405-412.

[3] Gang Wu, Hubiao Kang, Xiaoyang Zhang, Hongbo Shao, Liye Chu, Chengjiang Ruan. A critical review on the bio-removal of hazardous heavy metals from contaminated soils: Issues, progress, eco-environmental concerns and opportunities [J]. Journal of Hazardous Materials, 2010 $174(1-3) 1-8$.

[4] H. Wang, S. Lu, Z. Yao. EDTA-enhanced phytoremediation of lead contaminated soil by Bidens maximowicziana [J]. Journal of Enivironmental Science, 200719 (12) 1496-1499.

[5] I.D. Pulford, C. Watson. Phytoremediation of heavy metal-contaminated land by trees-a review [J]. Environment International, 200329 (4) 529-540.

[6] S.P. McGrath, J. Zhao, E. Lombi. Phytoremediation of metals, metalloids, and radionuclides [J]. Advances in Agronomy, 2002, 75 (02) 1-56.

[7] Ilya Raskin, Robert D. Smith, David E. Salt. Phytoremediation of metals: using plants to remove pollutants from the environment [J]. Current Opinion in Biotechnology, 19978 (2) 221-226.

[8] M.B. Kirkham. Cadmium in plants on polluted soils: Effects of soil factors, hyperaccumulation, and amendments [J]. Geoderma, 2006137 (1-2) 19-32.

[9] Zhu Huang, Xiao-Dong Pan, Ping-Gu Wu, Jian-Long Han, Qing Chen. Heavy metals in 
vegetables and the health risk to population in Zhejiang, China [J]. Food Control, 201436 (1) 248-252.

[10] Susan Tandy, Rainer Schulin, Bernd Nowack. The influence of EDDS on the uptake of heavy metals in hydroponically grown sunflowers [J]. Chemosphere, 200662 (9) 1454-1463.

[11] J.P. Ghestem, A. Bermond. EDTA extractability of trace metals in polluted soils: A chemical-physical study [J]. Environmental Technology, 199819 (4) 409-416.

[12] P.K. Andrew Hong, Chelsea Li, Shankha K. Banerji, Tulsi Regmi. Extraction, recovery, and biostability of EDTA for remediation of heavy metal-contaminated soil [J]. Journal of Soil Contamination, 19998 (1) 81-103.

[13] A. Piechalak, B. Tomaszewska, D. Baralkiewicz. Enhncing phytoremediative ability of Pisum sativum by EDTA application [J]. Phytochemistry, 200364 (7) 1239-1251.

[14] S. Li. Liaoning plant records [J]. Liaoning Science and Technology Press, Shenyang, China, 1992.

[15] K. Peng, X. Li, C. Luo, Z. Shen. Vegetation composition and heavy metal uptake by wild plants at three contaminated sites in Xiangxi area, China [J]. Journal of Environmental Science and Health Part A Environmental Science and Engineering \& Toxic and Hazardous Substance Control, 200641 (1) 65-76.

[16] S.H. Wei, Q.X. Zhou, X. Wang. Cadmium-hyperaccumulator Solanum nigrum L. and its accumulating characteristics [J]. Environmental science, 200526 (3) 167-171.

[17] Shuhe Wei, Qixing Zhou, Xin Wang, Kaisong Zhang, Guanlin Guo, Lena Qiying Ma. A newly-discovered Cd-hyperaccumulator Solanum nigrum L. [J]. Chinese Science Bulletin, 200550 (1) 33-38.

[18] Shuhe Wei, Qixing Zhou, Pavel V. Koval. Flowering stage characteristics of cadmium hyperaccumulator Solanum nigrum L. and their significance to phytoremediation [J]. Science of the Total Environment, 2006369 (1-3) 441-446.

[19] A.J.M. Baker, R.D. Reeves, A.S.M. Hajar. Heavy metal accumulation and tolerance in British populations of the metallophyte Thlaspi caerulescens J. \& C. Presl (Brassicaceae) [J]. New Phytologist, 1994127 (1) 61-68.

[20] H. Dahmani-Muller, F. van Oort, B. Gélie, M. Balabane. Strategies of heavy metal uptake by three plant species growing near a metal smelter [J]. Environmental Pollution, 2000109 (2) 231-238.

[21] Wei Liu, Wensheng Shu, Chongyu Lan. Viola baoshanensis, a plant that hyperaccumulates cadmium [J]. Chinese Science Bulletin, 200449 (1) 29-32.

[22] S.D. Bao. Agricultural and chemical analysis of soil. China agricultural press, 2005..

[23] Margarete Bucheli-Witschel, Thomas Egli. Environmental fate and microbial degradation of aminopolycarboxylic acids [J]. Fems Microbiology Reviews, 200125 (1) 69-106.

[24] L. Sanità di Toppi, R. Gabbrielli. Response to cadmium in higher plants [J]. Environmental and Experimental Botany, 199941 (2) 105-130.

[25] Paul Römkens, Lucas Bouwman, Jan Japenga, Cathrina Draaisma. Potentials and drawbacks of chelate-enhanced phytoremediation of soils [J]. Environmental Pollution, 2002116 (1) 109-121.

[26] R.N. Collins, G. Merrington, M.J. McLaughlin, C. Knudsen. Uptake of intact zinc-ethylenediaminetetraacetic acid from soil is dependent on plant species and complex concentration [J]. Environmental Toxicology and Chemistry, 200221 (9) 1940-1945. 
[27] L.H. Wu, Y.M. Luo, X.R. Xing, P. Christie. EDTA-enhanced phytoremediation of heavy metal contaminated soil with Indian mustard and associated potential leaching risk [J]. Agriculture, Ecosystems \& Environment, 2004102 (3) 307-318. 